\title{
DOES ALDOSE REDUCTASE HAVE A ROLE IN THE DEVELOPMENT OF THE OCULAR COMPLICATIONS OF DIABETES?
}

\author{
SUSAN LIGHTMAN \\ London
}

\begin{abstract}
SUMMARY
Diabetes mellitus has an effect on many organ systems including the eye, kidney and peripheral nerve. Many of these complications develop in animal models of diabetes, which has allowed some of the mechanisms of damage in target organs to be studied. Aldose reductase, an intracellular enzyme, converts glucose to sorbitol, and it is the intracellular accumulation of sorbitol which is thought to result in irreversible damage. In the diabetic eye the increased sorbitol accumulation in both the lens and the retina has been implicated in the pathogenesis of cataract and retinopathy, the major ocular complications of diabetes. In those experimental models which demonstrate characteristic diabetic complications, pharmacological inhibition of the enzyme aldose reductase has resulted in prevention of target organ damage. This paper summarises the experimental evidence upon which the clinical trials of aldose reductase inhibitors in diabetic patients have been initiated and the results of published drug trials in these patients.
\end{abstract}

\section{INTRACELLULAR GLUCOSE METABOLISM}

During normoglycaemia, glucose entering the cell is rapidly phosphorylated by the enzyme hexokinase and enters the Embden-Meyerhof pathway, providing the major aerobic energy source for the cell (Fig. 1). ${ }^{1}$ This pathway is fully saturated at normal glucose levels, so that if hyperglycaemia occurs the excess glucose cannot be metabolised by this pathway. The enzyme aldose reductase (AR) has a much lower affinity for glucose than hexokinase and significant amounts of glucose enter the sorbitol (or polyol) pathway only when its levels are raised. ${ }^{2} \mathrm{AR}$ converts glucose to the alcohol sorbitol, which is then further oxidised to fructose by the enzyme sorbitol dehydrogenase.

Correspondence to: Professor Susan Lightman, Institute of Ophthalmology, Moorfields Eye Hospital, City Road, London ECIV 2PD, UK.
$\mathrm{AR}$ and the sorbitol pathway were originally discovered in seminal vesicles and placenta and subsequently detected in tissues in which glucose transport is insulinindependent, ${ }^{3}$ which includes all those in which diabetic complications develop. In most of these tissues the normal physiological role of $\mathrm{AR}$ and the polyol pathway is unknown and no physiologically significant amount of sorbitol is detectable. ${ }^{4}$

\section{ANIMAL MODELS OF DIABETIC COMPLICATIONS}

Animals such as rats can be rendered diabetic by administration of drugs such as streptozotocin that are toxic to the pancreatic islets. One of the major problems with these animals is that they are sick, become ketotic and often succumb to infection, so that they do not live very long. The galactose-fed animal on the other hand, be it rat or dog, has been found to develop many of the complications of chronic diabetes but remains well with a normal blood glucose level. ${ }^{1}$ It is known that galactose is a very good substrate for AR, much better than glucose, and galactose feeding results in the intracellular accumulation of the alcohol galactitol, which is not further metabolised by sor-

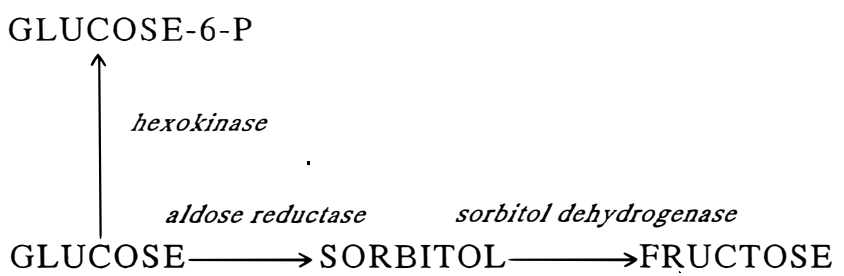

aldose reductase

GALACTOSE $\longrightarrow$ GALACTITOL

Fig. 1. Intracellular glucose and galactose metabolic pathways. 
bitol dehydrogenase. Galactitol therefore accumulates more quickly than sorbitol and results in more rapid onset of cellular damage. ${ }^{4}$

Damage is thought to occur in the cell in which either sorbitol or galacticol accumulates by the creation of hypertonicity and the subsequent osmotic attraction of water. This occurs because the polar nature of these
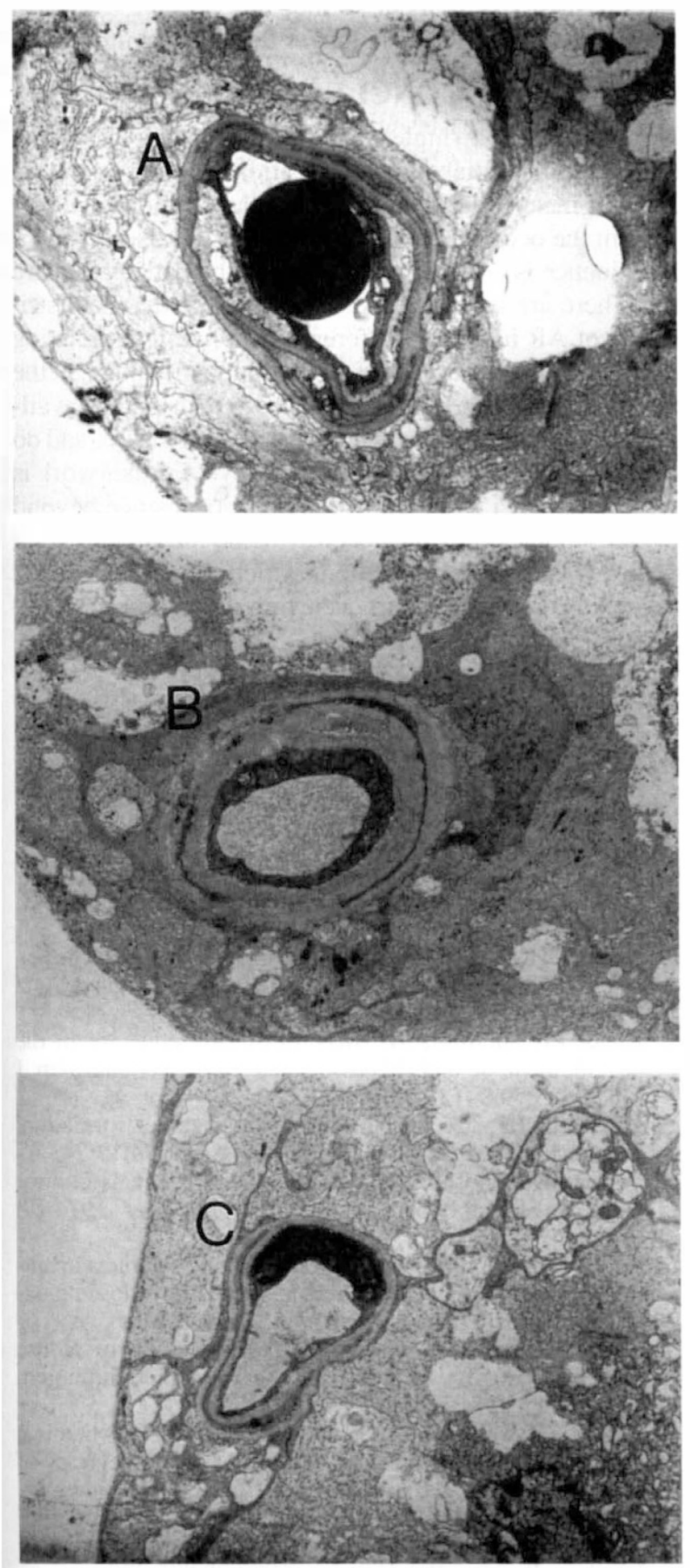

Fig. 2. Electron micrographs of retinal capillary to show basement membrane: $(A)$ in control rat; $(B)$ in galactose-fed rat; $(C)$ in rat fed galactose and aldose reductase inhibitor. (Courtesy of Dr. W. G. Robison.) alcohols prevents their easy penetration of membranes and subsequent removal from the cell by diffusion. The increase in intracellular fluid causes the cell to swell with eventual damage to its membranes which then has secondary effècts on cell homeostasis. ${ }^{5}$

\section{ALDOSE REDUCTASE AND CATARACT FORMATION}

Cataracts develop in both diabetic and galactose-fed animals at a rate directly dependent on the amount of AR present in the lens. ${ }^{4}$ In mice, where lens AR levels are extremely low, cataracts do not develop in either of these metabolic states. In diabetic rat lenses AR activity has been found to increase, whereas sorbitol dehydrogenase activity decreases. ${ }^{6}$ Using immunohistochemical techniques with antibodies against purified AR, there is increasing staining of the lens with the onset of diabetes. ${ }^{7}$

Using drugs which inhibit AR (aldose reductase inhibitors: ARIs), the onset of cataracts can be significantly delayed in these experimental animals if the ARI is given at the onset of the disease. ${ }^{8}$ Intervention studies demonstrated that the cataractogenic process can only be reversed during the early stages prior to the onset of nuclear cataract. ${ }^{9}$ Interestingly, biochemical analysis of these cataractous lenses revealed no difference in the levels of glycosylated proteins between treated and untreated rats. Since only the lenses from the treated rats remained clear, these results indicate that there is no relationship between non-enzymatic glycosylation and the polyol pathway and that non-enzymatic glycosylation does not appear to be responsible for cataract formation in this situation. ${ }^{10}$ Unfortunately, the role of AR in cataract formation in human diabetics has not been established."

ARIs have also been administered topically in diabetic rats. There was decreased cataract formation in these rats over a 4-month period, which was associated with decreased lens sorbitol in the treated rats as compared with controls. ${ }^{12}$

\section{KERATOPATHY}

Diabetic corneal epithelium can heal more slowly when traumatised and in studies with diabetic or galactose-fed

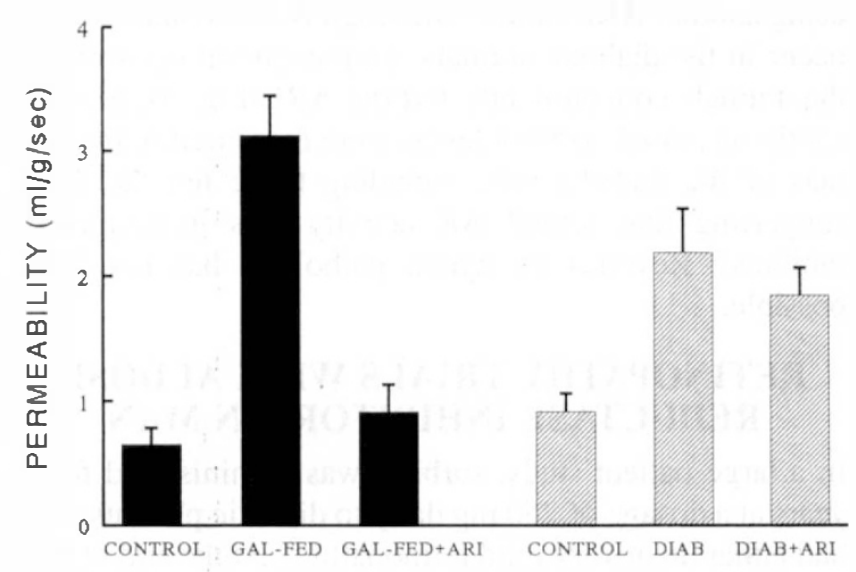

Fig. 3. Blood-retinal barrier permeability in galactose-fed (for $11+$ months) and diabetic (for $11+$ months) rats. 
animals denuded corneal epithelium was found to reepithelialise more slowly. ${ }^{13}$ This delay was prevented by administration of an ARI, either orally or topically, and AR has been detected in the cornea in both epithelium and endothelium. ${ }^{14}$ In patient studies, healing of diabetic corneal epithelium was achieved with administration of the topical ARI in patients in whom spontaneous healing had not occurred. ${ }^{15}$

\section{RETINOPATHY}

The classic histopathological features of diabetic retinopathy are pericyte degeneration, basement membrane thickening, microaneurysm formation and capillary nonperfusion. Neovascularisation can occur as a consequence of retinal ischaemia. All of these features have now been reproduced in the animal models, particularly the galactose-fed beagle dog, demonstrating that stressing the polyol pathway alone can give rise to all the characteristics of the retinopathy seen in diabetic patients. ${ }^{16}$ Again, all of these features are inhibited in a dose-dependent manner by the concomitant administration of an ARI at the onset of the disease state. ${ }^{17}$

Macula oedema due to loss of integrity of the bloodretinal barrier (BRB) is a common cause of loss of vision in diabetic patients. ${ }^{18}$ Pericyte-endothelial cell interaction is thought to be important in maintaining the BRB and the combination of pericyte loss together with endothelial cell basement membrane thickening could result in its functional breakdown. Increased retinal capillary basement membrane thickening occurs in the galactose-fed rat and is inhibited by concomitant administration of an ARI (Fig. 2). In order to examine whether this morphological increase in basement membrane thickness is associated with a functional increase in permeability, the permeability of the BRB to small molecular weight non-transported solutes was quantitatively assessed in vivo at various time points after galactose feeding with and without concomitant administration of an ARI (sorbinil). ${ }^{19}$ BRB breakdown occurred after 11 months of galactose feeding and was totally prevented by administration of the ARI (Fig. 3). Using similar techniques, the same study was repeated in diabetic rather than galactose-fed rats and using another ARI, statil. ${ }^{20}$ Although BRB breakdown did occur in the diabetic animals, no prevention occurred in the animals concomitantly fed the ARI (Fig. 3). Significantly increased sorbitol levels were measured in the retinas of the diabetic rats, including those fed the ARI, suggesting that retinal AR activity was incompletely inhibited. Reversal of retinal pathology has not been possible.

\section{RETINOPATHY TRIALS WITH ALDOSE REDUCTASE INHIBITORS IN MAN}

In a large patient study, sorbinil was administered for 3 years at a dosage of $250 \mathrm{mg}$ daily to diabetic patients who had either no or very mild retinopathy. ${ }^{21}$ At the end of this time there was no significant difference in the severity of retinopathy between the two groups of patients, although a statistically significant slower increase in microaneurysms was apparent in the treated group. The real significance of this finding is uncertain. A different ARI (ponalrestat) was given to a small group of patients with minimal background retinopathy for a maximum of 12 months, also with no significant effect. ${ }^{22}$ These trials have been carried out for a relatively short period of time in the natural history of diabetic retinopathy and the results of the trials conducted over a longer time are awaited.

\section{CONCLUSIONS}

The concept of a single final common pathway for the pathogenesis of diabetic complications is a very exciting one if it means that its pharmacological inhibition could prevent the occurrence of complications. The experimental evidence is convincing but to date the patient data are not. There are several reasons for this. Firstly, the distribution of AR in man is different from that in rat and dog and little is known about its regulation, particularly in the retina. Secondly, there is no evidence in man that the available ARIs at the doses used actually get into the eye and do inhibit the types of AR present in the eye. Further work is vital in this area to answer these questions, since beyond any reasonable doubt the best way in the future of treating these devastating complications which can blind diabetic patients is to prevent them occurring in the first place.

Key words: Aldose reductase, Cataract, Diabetes, Pericyte, Retinopathy.

\section{REFERENCES}

1. Kador PF, Kinoshita JH, Sharpless NE. Aldose reductase inhibitors: a potential new class of agents for the pharmacological control of certain diabetic complications. J Med Chem 1985;28:841-9.

2. Kador PF, Robison GW Jr, Kinoshita JH. The pharmacology of aldose reductase inhibitors. Annu Rev Pharmacol 1985; 25:691-714.

3. Hers HG. Le mécanisme de la transformation de glucose en fructose par les vesicules seminals. Biochim Biophys Acta 1956;22:202-3.

4. Kador PF, Kinoshita JH. Role of aldose reductase in the development of diabetes-associated complications. Am J Med 1985;79:8-12.

5. Kinoshita JH. Mechanisms initiating cataract formation. Proctor Lector. Invest Ophthalmol Vis Sci 1974;13:713.

6. Varma SD, Kinoshita JH. The absence of cataracts in mice with congenital hyperglycemia. Exp Eye Res 1974;19: 577-82.

7. Kador PF, Akagi Y, Kinoshita JH. Diabetic cataracts in animal models: prevention and reversibility with aldose reductase inhibitors. Diabetic Med 1985;2:194-6.

8. Kador PF, Akagi Y, Kinoshita JH. The effect of aldose reductase and its inhibition on sugar cataract formation. Metabolism 1986;35:15-9.

9. Reddy VN, Schwass D, Chakrapani B, et al. Biochemical changes associated with the development and reversal of galactose cataracts. Exp Eye Res 1976;23:483-93.

10. Chiou SH, Chylack Lt Jr, Bunn FH, et al. Role of nonenzymatic glycosylation in experimental cataract formation. Biochem Biophys Res Commun 1980;95:895-901.

11. Jedziniak JA, Chylack Lt Jr, Cheng HM, Gillis MK, Kalustian NA, et al. The sorbitol pathway in the human lens: aldose reductase and polyol dehydrogenase. Invest Ophthalmol Vis Sci 1981;20:314-26. 
12. Kador PF, Kinoshita JH. Diabetic and galactosaemic cataracts. Ciba Found Symp 1984;106:110-31.

13. Fukushi S, Merola LO, Tanaka M, Datiles M, Kinoshita JH. Re-epithelialization of denuded corneas in diabetic rats. Exp Eye Res 1980;31:611-21.

14. Datiles MB, Kador PF, Fukui HN, Hu TS, Kinoshita JH. Corneal re-epithelialization in galactosemic rats. Invest Ophthalmol Vis Sci 1983;24:563-9.

15. Akagi Y, Yajima Y, Kador PF, Kuwabara T, Kinoshita JH. Localization of aldose reductase in the human eye. Diabetes 1984;33:562-6.

16. Cobo LM. Aldose reductase and diabetic keratopathy. Ann Intern Med 1984;101:82-91.

17. Engerman RL, Kern TS. Experimental galactosaemia produces diabetic-like retinopathy. Diabetes 1984;33:97-100.

18. Klein R, Klein B, Moss E, Davis M, DeMets, D. The Wis- consin epidemiologic study of retinal retinopathy. IV. Diabetic macular edema. Ophthalmology 1984;91:1464-74.

19. Lightman S, Rechthand E, Terubayashi H, Palestine A, Rapoport S, Kador P. Permeability changes in blood retinal barrier.of galactosemic rats are prevented by aldose reductase inhibitors. Diabetes 1987;36:1271-5.

20. Lightman S, Pinter G, Yuen L, Bradbury M. Permeability changes at blood-retinal barrier in diabetes and effect of aldose reductase inhibition. Am Physiol 1990;259:R601-5.

21. Sorbinil Retinopathy Trial Research Group. A randomised trial of sorbinil, an aldose reductase inhibitor, in diabetic retinopathy. Arch Ophthalmol 1990;108:1234-44.

22. Tromp A, Hooymans JM, Barendsen BC, van Doormaal JJ. The effects of an aldose reductase inhibitor on the progression of diabetic retinopathy. Doc Ophthalmol 1991;78: 153-9. 